\title{
Research on Thermal Process of MIG Welding of Aluminum Alloy with Longitudinal Magnetic Field
}

\author{
Sheng Zhu, Qiwei Wang*, Fengliang Yin, Yuanyuan Liang and Xiaoming Wang \\ National Key Laboratory for Remanufacturing, Academy of Armored Forces Engineering, Beijing 100072, China
}

\begin{abstract}
In order to study MIG welding process of aluminum alloy with longitudinal magnetic field, thermal efficiency with longitudinal magnetic field was analyzed, as well as softening behavior of heat-affected zone (HAZ) and base metal were investigated. The results showed that under the action of longitudinal magnetic field, welding current decreased and resultingly total heat input reduced as the exciting current increased, meanwhile at the anode surface current density and heat flux density decrease in the arc core and rise at the edge of arc, which made arc thermal efficiency increasing and melting efficiency decreasing. As a result of action of the magnetic field, the trend of grain growth of HAZ slowed down and the influence on base metal of heat input decreased. When the exciting current was 20A, microhardness of HAZ and base metal improved evidently. However, as the exciting current continued to increase, the effect of magnetic field on softening behavior did not change significantly.
\end{abstract}

Keywords: Magnetic field, MIG welding, thermal process, softening behavior.

\section{INTRODUCTION}

Welding thermal process consist in the whole welding process. Welding heat input and the distribution of heat flux influence the crystal structure, residual stresses and welding distortion of the weld zone and HAZ, sequentially to determine the final weld quality [1]. Therefore, the study on the welding thermal process has always been an important research subject in welding field. A variety of welding methods and techniques has been developed to reduce the impact of heat input. The applications of electromagnetic field in welding is a new developed technology in recent years, by which the welding arc shape, melting droplet transition and crystallization process of liquid metal in the molten pool are influenced through additional magnetic field, accordingly refining weld crystal organization and improving mechanical properties [2]. Another important action of magnetic field has not been noticed widely yet, which is to change the arc shape by the magnetic field and thus to affect the heat input and heat flux distribution, thereby decreasing the influence of welding heat input on the base material, particularly to reduce the welding deformation and improve welding quality when welding the thin pieces metal. In this paper, the thermal efficiency and melting efficiency in MIG welding of aluminum alloy with longitudinal magnetic field were analyzed, as well as the influence on softening behavior was investigated.

\section{EXPERIMENTAL MATERIAL AND METHODS}

In the study the base metal used was 6061 aluminum alloy plate which size was $300 \times 300 \times 15 \mathrm{~mm}$ and welding wire used was ER5356 which diameter was $1.2 \mathrm{~mm}$. The

*Address correspondence to this author at the National Key Laboratory for Remanufacturing, Academy of Armored Forces Engineering, Beijing 100072, China; Tel: +86-010-66717640 (Office), +86-15120029168 (Mobile); Fax: +86-010-66717650;

E-mails: zusg@sina.com,wangqw4@yahoo.com.cn chemical compositions of the base metal and welding wire are shown in Table 1. A TPS-4000 digital DC pulsed MIG welding source was used. Shielding gas was argon, which purity is $99.99 \%$ and the flow rate is $15 \mathrm{~L} / \mathrm{min}$. Additional longitudinal magnetic field was produced via the excitation coil installed on the welding torch. The excitation coil was made of enameled wire which diameter was $2.5 \mathrm{~mm}$. The turns of excitation coil was 230, and the range of magnetic flux density was $0 \sim 30 \mathrm{mT}$. The direction of magnetic lines of flux paralleled the arc axis, and made a symmetrical distribution relative to arc axis. Excitation current was provided by a self-designed excitation power, which excitation current and frequency could be adjusted. Diagram of welding equipment is shown in Fig. (1). In the experiment beads were made by choosing different welding parameters and exciting current intensity. These parameters were shown in Table 2. After welding, the geometry of bead was measured and microstructure of HAZ was observed. The microhardness of different zone was measured including coating, fusion line, HAZ and base metal. Hardness measurement points are shown in Fig. (2). Heat flux density and current density of the arc with longitudinal magnetic field were simulated by using ANSYS FEA software.

Table 1. Compositions of Base Metal and Filler Wire (wt. \%)

\begin{tabular}{|c|c|c|c|c|c|c|c|c|c|}
\hline Material & $\mathbf{S i}$ & $\mathbf{F e}$ & $\mathbf{C u}$ & $\mathbf{M n}$ & $\mathbf{M g}$ & $\mathbf{C r}$ & $\mathbf{Z n}$ & $\mathbf{T i}$ & $\mathbf{A l}$ \\
\hline \hline 6061 & $0.4 \sim 0.8$ & 0.7 & $0.15 \sim 0.4$ & 0.15 & $0.8 \sim 1.2$ & $0.04 \sim 0.35$ & 0.25 & 0.15 & $\mathrm{Bal}$ \\
\hline ER5356 & 0.25 & 0.10 & 0.10 & $0.05 \sim 0.2$ & $4.5 \sim 5.5$ & $0.05 \sim 0.20$ & 0.10 & & $\mathrm{Bal}$ \\
\hline
\end{tabular}

\section{RESULTS AND ANALYSIS}

3.1. Welding Thermal Process under the Action of Additional Magnetic Field

The physical model of welding heat source involves two aspects: how much heat is applied to the weldment and how 
Table 2. Welding and Electromagnetic Field Parameters

\begin{tabular}{|c|c|c|c|c|c|c|}
\hline $\begin{array}{c}\text { Weld } \\
\text { No. }\end{array}$ & $\begin{array}{c}\text { Welding Speed } \\
{\left[\mathbf{m m} \cdot \mathbf{s}^{-1}\right]}\end{array}$ & $\begin{array}{c}\text { Wire Feed Speed } \\
{\left[\mathbf{m}_{\mathbf{m i n}}^{-1}\right]}\end{array}$ & $\begin{array}{c}\text { Magnetic Field } \\
\text { Frequency [Hz] }\end{array}$ & $\begin{array}{c}\text { Exciting Current } \\
{[\mathbf{A}]}\end{array}$ & $\begin{array}{c}\text { Welding } \\
\text { Current [A] }\end{array}$ & $\begin{array}{c}\text { Welding Voltage } \\
\text { [V] }\end{array}$ \\
\hline \hline 1 & 24 & 8 & 0 & 0 & 136 \\
\hline 2 & 24 & 8 & 10 & 10 & 130 & 19 \\
\hline 3 & 24 & 8 & 10 & 20 & 112 & 19 \\
\hline 4 & 24 & 8 & 10 & 25 & 105 & 19 \\
\hline
\end{tabular}

the heat is distributed in weldment. The majority of total energy in welding process is provided by the welding arc, while a small portion is generated by the electrode. According to the law of conservation of energy [3], the total energy balance can be expressed as:

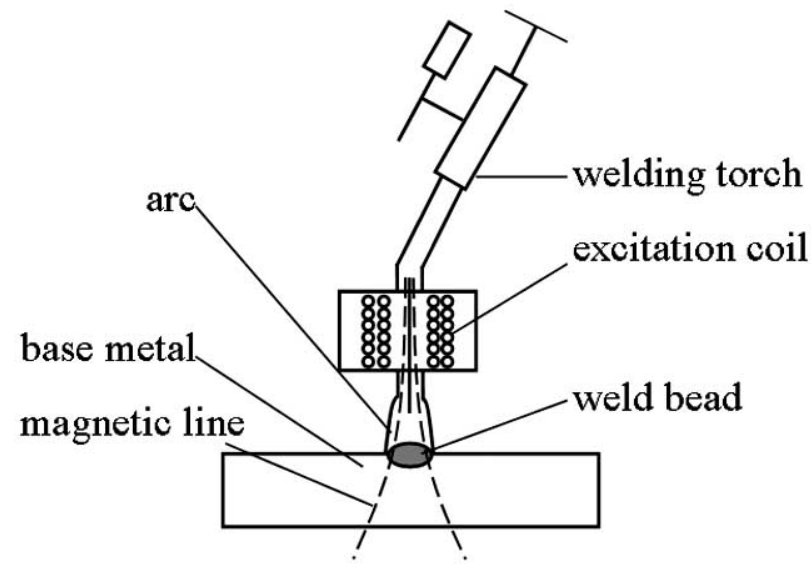

Fig. (1). Diagram of welding equipment.

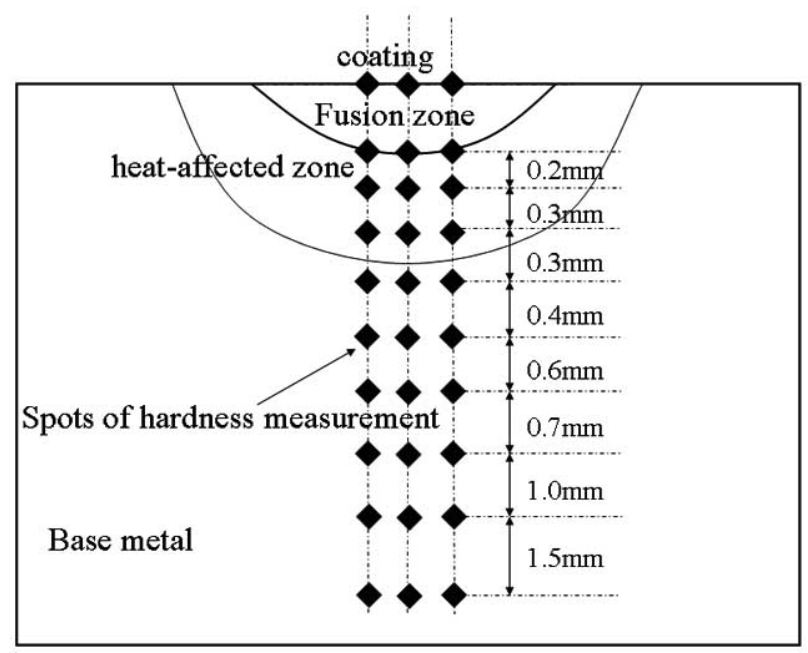

Fig. (2). Locations of measured points.

$E_{\text {total }}=E_{\text {losses }}+E_{f z}+E_{b m}$

Where $E_{\text {total }}$ is the total energy generated by the arc and electrodes resistance, $E_{\text {losses }}$ is the energy lost to the surrounding environment, $E_{f z}$ is the energy used to melt the fusion zone (including the latent heat of fusion), $E_{b m}$ is the energy passed to the base metal (used to form the HAZ and heat base metal). $E_{f z}+E_{b m}$ is the total energy transferred to the work piece, $E_{f z}$ is used for melting metal, called effective energy. Therefore, the arc heat efficiency $\eta_{a}$, and the melting efficiency $\eta_{m}$, can be defined as:

$\eta_{a}=\frac{E_{f z}+E_{b m}}{E_{\text {total }}}$

$\eta_{m}=\frac{E_{f z}}{E_{f z}+E_{b m}}$

During the welding process voltage remained the same and welding current decreased with the increase of exciting current, as is shown in Fig. (3). The reason is that charged particles circumgyrated under the action of Lorentz force and the moving path of charged particles changed from the straight line to spiral, which made total path and the distance of the conduction current increased, as well as the arc resistance increased, thus welding current reduced [4].

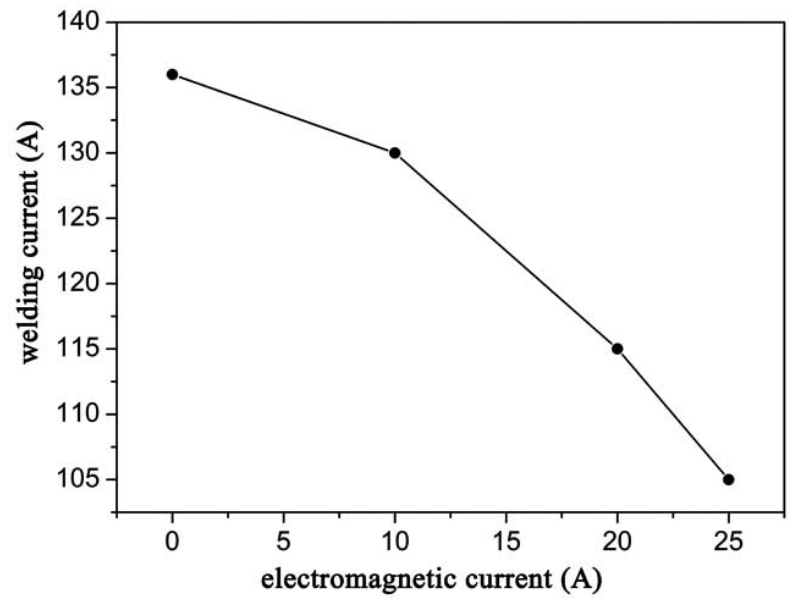

Fig. (3). Effects of electromagnetic current intensity on welding current.

As arc voltage remained the same and the welding current decreased under the action of magnetic field, the heat input $E_{\text {total }}$ reduced. Arenas gave the approximate empirical equation of computing the arc heat efficiency by generalizing Tsai and Eagar's experimental data [5, 6]. The equation can be expressed as:

$\eta_{a}=7.48 \frac{I^{0.63} R_{\mathrm{c}}^{2}}{L^{0.8} I U}$ 
Where, $L, I, U$ and $R_{\mathrm{c}}$ represent length of arc, welding current, welding volt and radius of arc respectively. So under action of longitudinal magnetic field, arc expanded and radius of arc increased and welding current reduced, which made arc heat efficiency increased. But owing to the total heat input reduced, the total effective energy of arc decreased. Guan Qiao gave method of testing welding thermal efficiency and melting efficiency under different weld heat input, and the result showed that effective energy factor of thermal decreased as effective heat input of arc decreased, namely the melting efficiency $\eta_{m}$ decreased [7]. DuPont had demonstrated that melting efficiency could be predicted from the welding parameters and material properties by the equation 5 [8].

$\eta_{m}=0.5 \exp \left(\frac{-175}{\eta_{a} U \mathrm{~V} / E \alpha \nu}\right)$

In the equation $5, \eta_{a} U I$ is effective energy of arc, $\mathrm{v}$ is welding speed, $E$ is the total enthalpy change due to melting, $\alpha$ is the thermal diffusivity at $300 \mathrm{~K}, v$ is kinematic viscosity at the melting point. DuPont's research showed that melting efficiency decreased as total energy decreased, and melting efficiency increased rapidly when welding speed increased. But when welding speed increased to some extent, melting efficiency reached a maximum.

The comparison of the effective heat input under different exciting current can be transformed into the comparison of the cross-sectional area of fusion zone by the equation (6) [9].

$$
E_{f z}=F \mathrm{v} \rho\left(\int_{T_{0}}^{T m} c d T+H\right)
$$

Where $F$ is the cross-sectional area of fusion zone, $\mathrm{v}$ is the welding speed, $\rho$ is the density of weld material, $c$ is heat capacity, $H$ is the latent heat of fusion, $T_{0}$ is the environment temperature, $T_{m}$ is the melting point. As welding speed and density of weld material are constant, effective heat input ratio $\delta$ under different exciting current can be expressed as,

$\delta=\frac{E_{f z 1}}{E_{f z 2}}=\frac{F_{1}}{F_{2}}$

Where $E_{f z 1}$ and $E_{f z 2}$ are the effective weld heat input under different exciting current, $F_{1}$ and $F_{2}$ are the cross-sectional area of fusion zone under exciting current. As the fusion line shape can approximately be seen as parabolic shape and weld width and penetration are known, the equation of fusion line can be expressed as,

$y=-\frac{4 h}{b^{2}} x^{2}+h$

So the cross-sectional area of fusion zone can be got according to equation (9):

$F=\int_{-\frac{b}{2}}^{\frac{b}{2}}\left(-\frac{4 h}{b^{2}} x^{2}+h\right) d x=\frac{2}{3} b h$

Where $b$ is weld width and $h$ and is penetration. The crosssectional area of fusion zone under the action of different exciting current is shown in Fig. (4), from which it is observed that the cross-sectional area of fusion zone decreased with the exciting current increasing, so the effective weld heat input $E_{f z}$ reduced according to the equation (7).

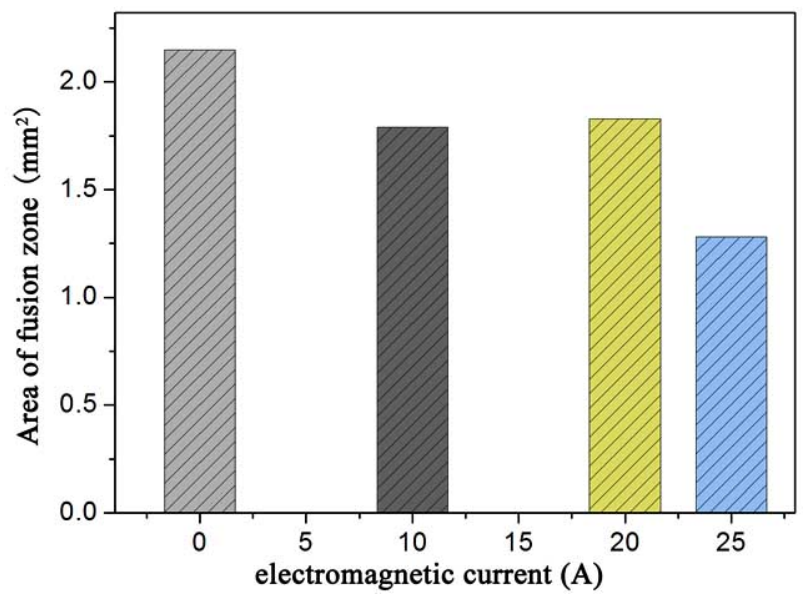

Fig. (4). Cross-sectional area of fusion zone under different exciting current intensity.

\subsection{Current Density and Heat Flux Density under the Action of Additional Magnetic Field}

Current density distribution of welding arc is one of the most fundamental matters. It affects the distribution of heat flux directly and decided the final welding quality. Move of charged particle is the main mode by which arc transmits heat energy to welding pool. So move of charged particle under the action of longitudinal magnetic field is analyzed.

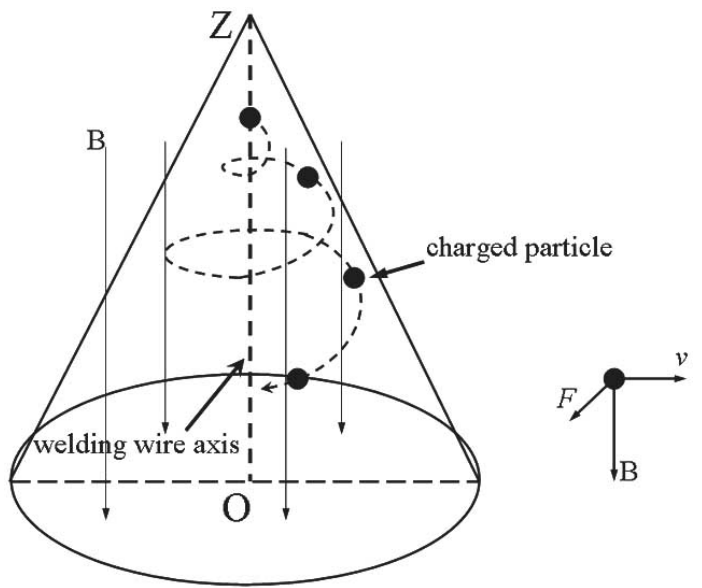

Fig. (5). Move of charged particle under the action of longitudinal magnetic field.

When longitudinal magnetic field is introduced into welding process, charged particle was act by Lorentz force as is shown Fig. (5). Under the action of Lorentz force $F$ charged particle rotate around the welding wire axis and away from the welding wire axis, which made shape of arc expand and density of charged particle decrease. As density of charged particle decrease, current density decreased and heat flux decreased. Fig. (6) and Fig. (7) gave the simulated results of current density of arc under the action of different magnetic field condition, which can refer to Ref. [10]. From the simulated results it can be concluded that at the tip of welding wire current density has maximum and the max is $1.25 \times 10^{8}$ when the welding current is $136 \mathrm{~A}$. As the distance 


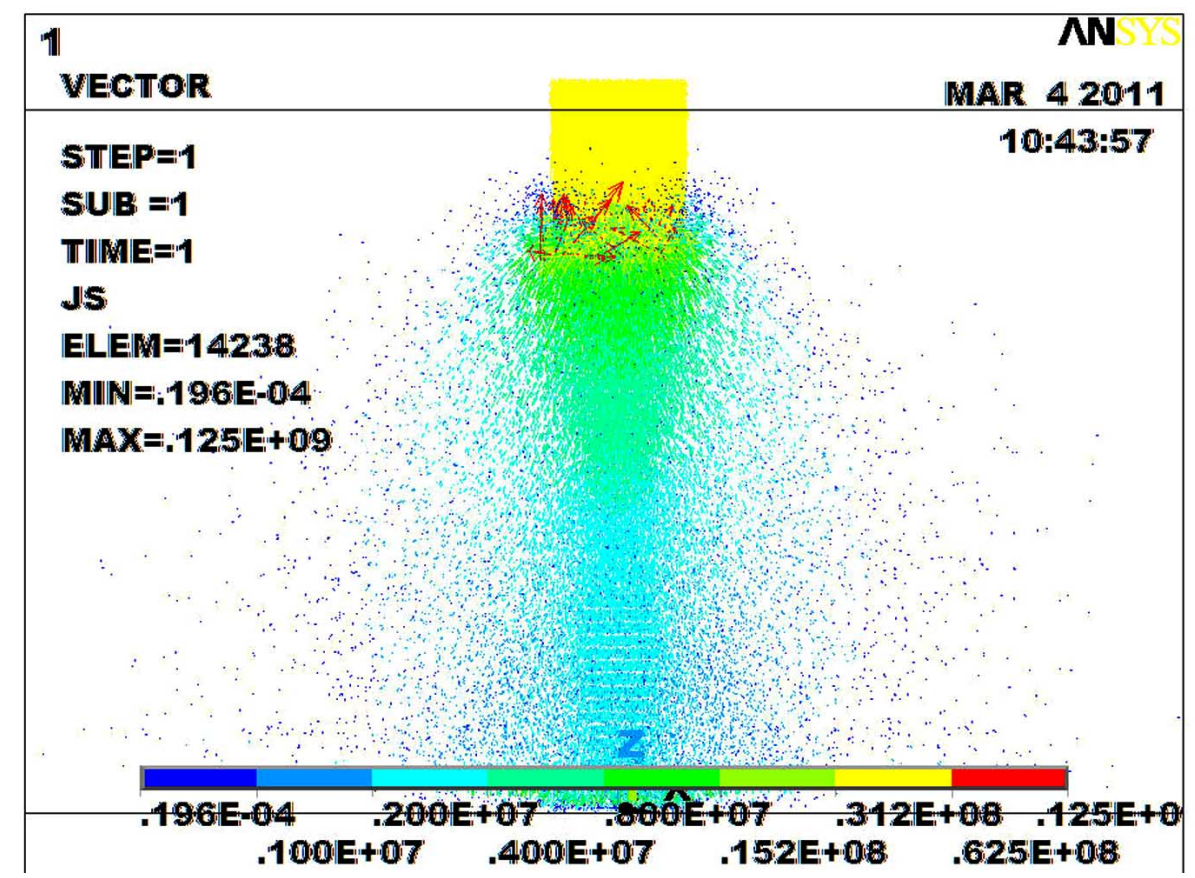

Fig. (6). Current density distribution without longitudinal magnetic field.

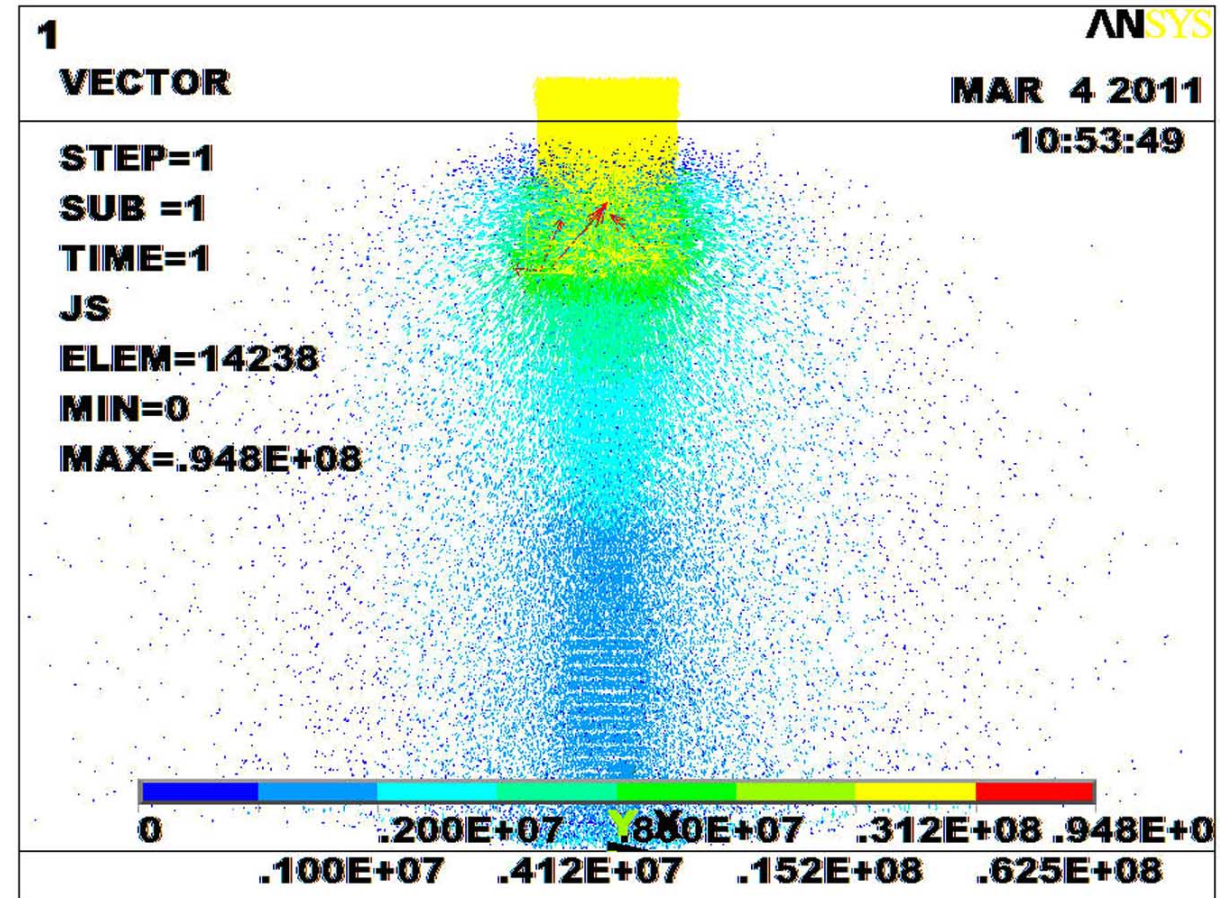

Fig. (7). Current density distribution with longitudinal magnetic field.

from cathode increased, current density decreased gradually. When longitudinal magnetic field is introduced into welding process and other process parameters are invariable, average of current density decreased and the max of current density is $0.9 \times 10^{8}$.

Fig. (8) and Fig. (9) show heat flux distribution and current density distribution on the anode under different magnetic field conditions. It is seen that the rule of current density distribution and heat flux are similar. Heat flux density and current density on the anode decreased in the arc core and increased at the edge of arc when longitudinal magnetic field is introduced into welding process. As radial distance to arc core increase, current density and heat flux on the anode decrease. Yet velocity of decrease is different. Current density and heat flux of arc with additional longitudinal magnetic field is slower than that having no longitudinal magnetic field. Consequently at the edge of arc current density and heat flux of arc with longitudinal magnetic field are greater than arc without longitudinal magnetic field. 


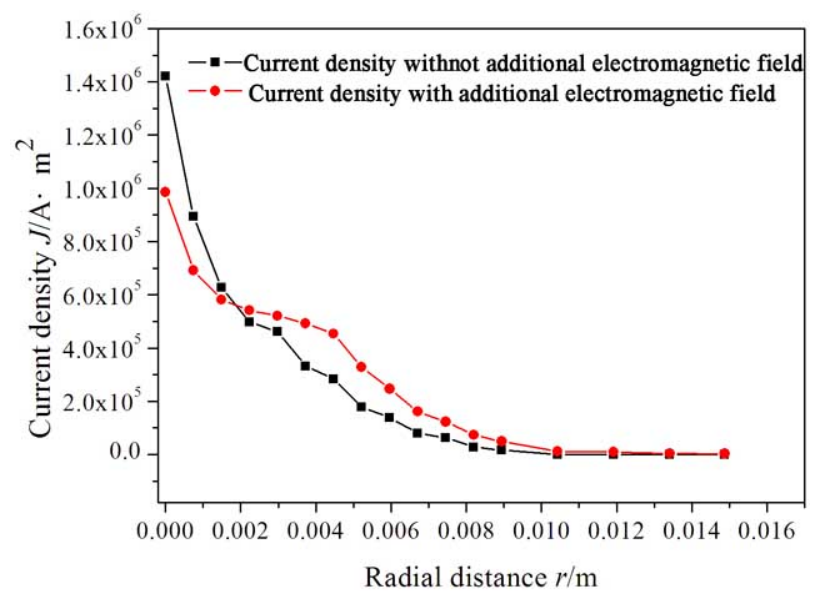

Fig. (8). Current density distribution at anode.

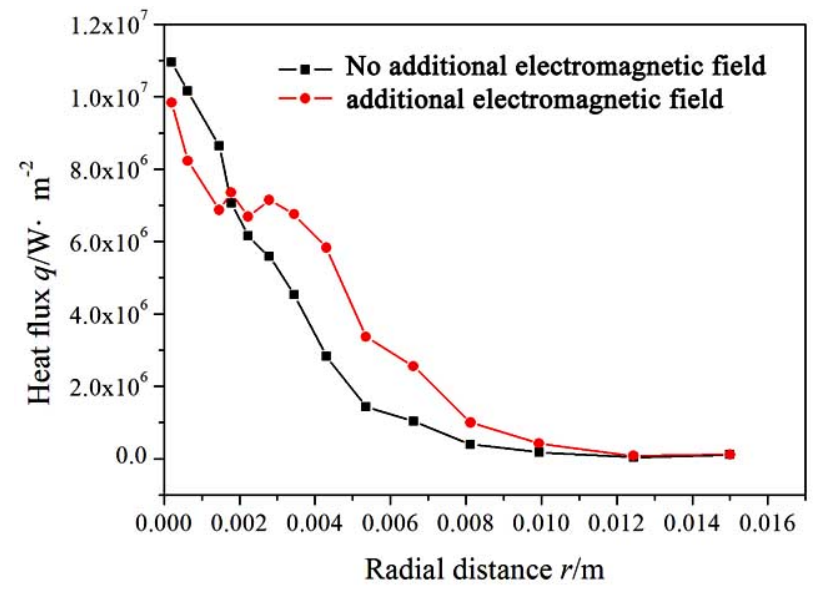

Fig. (9). Heat flux distribution at anode.

\subsection{Softening Behavior of HAZ under the Action of Additional Magnetic Field}

Microstructure and properties of base metal changed owing to the heat input decreasing and the redistribution of heat flux on the surface of base metal under the action of magnetic field.

Fig. (10) shows the microstructure of HAZ under different exciting current intensity. It can be observed when the exciting current is $0 \mathrm{~A}$, the organization of HAZ became thick obviously and apparently belonged to the typical overheated organizations. As the exciting current increased, the effect of heat input on base material organizations reduced and the grain growth trend of HAZ slowed down. When the exciting current is between $10 \mathrm{~A}$ and $20 \mathrm{~A}$, effectiveness of grain refining is the best. Therefore when the longitudinal magnetic field is suitable, it is beneficial to improve the grain organization of HAZ.

Fig. (11) shows trend of micro-hardness of HAZ and base metal under different exciting current intensity. It can be observed that softening behavior of HAZ due to weld heat input is obvious and magnetic field has an obvious effect to hardness of base metal. The farther the distance from the fusion line, the greater the hardness gradually became. When the exciting current intensity was 0 , the base metal hardness was lower. As exciting current intensity increased, the overall hardness of base metal increased. Base metal hardness is the greatest when exciting current intensity is 20 A. However, when the exciting current intensity continued to increase, the base metal hardness did not change significantly. These results show that the impact of heat input on softening behavior of HAZ and base metal becomes weaker under the action of longitudinal magnetic field.

Fig. (12) shows cross section and HAZ of bead under different exciting current intensity. It is observed that shape
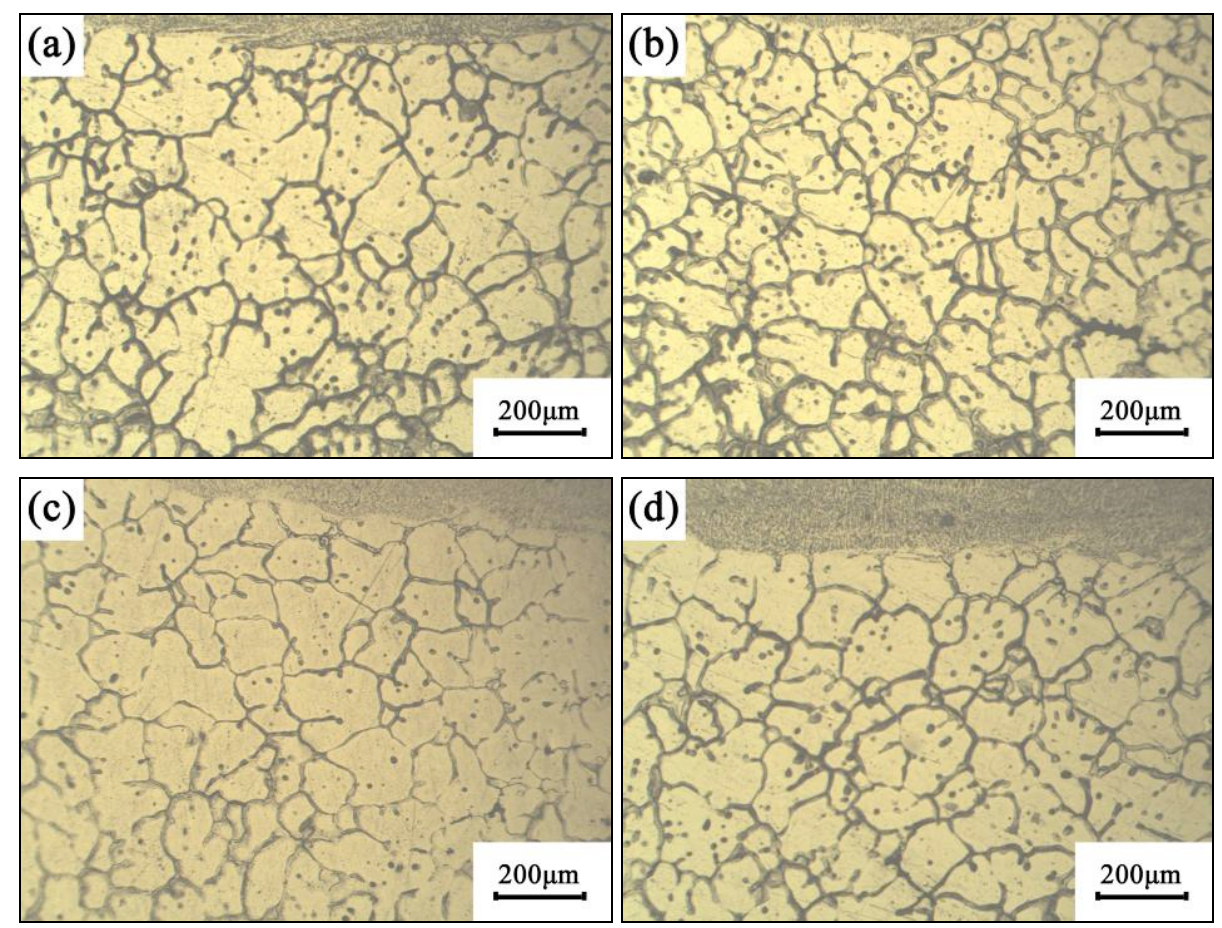

Fig. (10). Microstructure of HAZ under different exciting current intensity. (a) $I=0 \mathrm{~A}$; (b) $I=10 \mathrm{~A}$; (c) $I=20 \mathrm{~A}$; (d) $I=25 \mathrm{~A}$. 


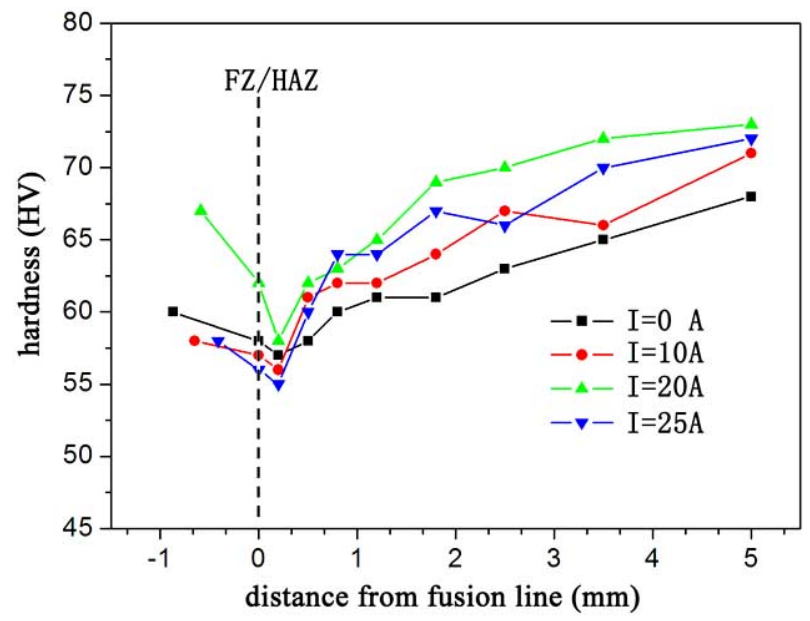

Fig. (11). Hardness distribution of HAZ and base metal under different exciting current intensity. change with different magnetic field conditions, which are shown in Fig. (13). The penetration was $0.87 \mathrm{~mm}$ when there have no additional longitudinal magnetic field. Under the action of magnetic field as exciting current intensity increased, penetration of bead reduced. While the exciting current intensity is $25 \mathrm{~A}$, penetration reduced to $0.41 \mathrm{~mm}$. As the exciting current intensity changed from 0 to $25 \mathrm{~A}$, the width of HAZ changed little and average width was $0.6 \mathrm{~mm}$. The overall impact of heat input on the base metal should be the total of penetration and width of HAZ, so the depth of influence on the base metal reduced with the exciting current intensity increasing.

\section{CONCLUSIONS}

During the welding process with additional longitudinal magnetic field, welding current and total heat input decreased as the exciting current increased, meanwhile arc
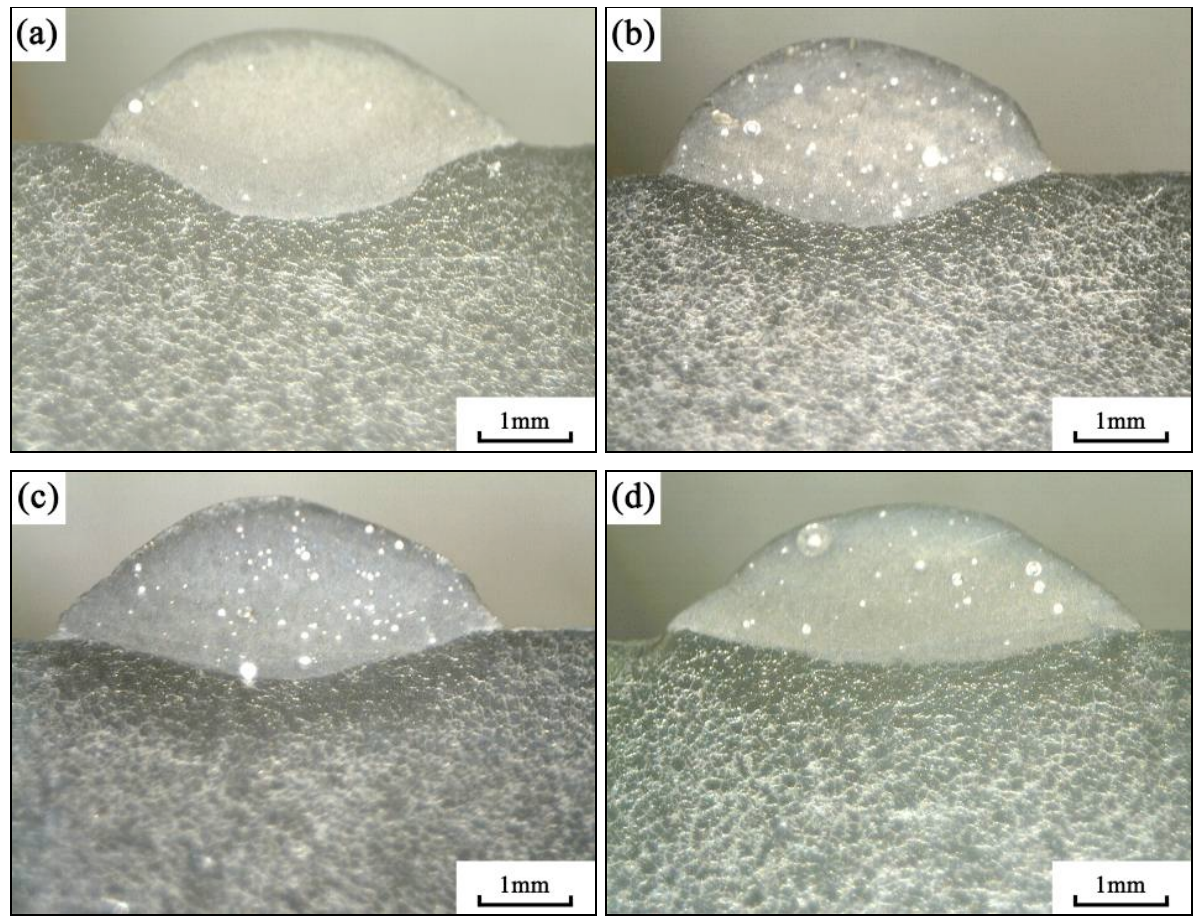

Fig. (12). Cross section and HAZ under different exciting current intensity. (a) $I=0 \mathrm{~A}$; (b) $I=10 \mathrm{~A}$; (c) $I=20 \mathrm{~A}$; (d) $I=25 \mathrm{~A}$.

of cross section changed under the action of longitudinal magnetic field. Penetration of bead and width of HAZ had a

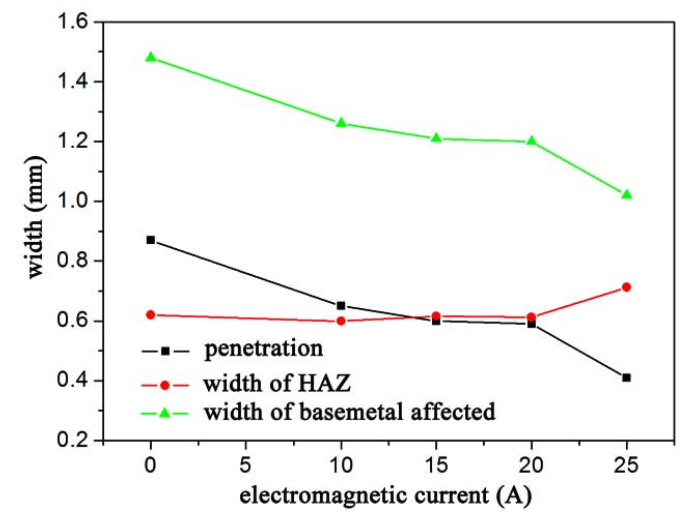

Fig. (13). Effects of magnetic condition on penetration and width of HAZ. thermal efficiency increased and melting efficiency decreased. Thermal actions of arc weaken in long direction and cover with more area in lateral direction with exciting current intensity increasing, which made bead width increased, penetration and area of fusion zone reduced, as well as influence extent of heat input on base metal decreased. The trend of the grain growth of HAZ slows down and softening behavior lower with exciting current intensity increasing. As the exciting current intensity was $20 \mathrm{~A}$, the micro-hardness of HAZ and base metal improves evidently. But when exciting current intensity continued to increase, microstructure and mechanical property of HAZ did not change obviously.

\section{ACKNOWLEDGEMENTS}

The authors gratefully acknowledge support for this study from the National Natural Science Foundation of 
China (No. 50975286; No. 50735006) and Foundation (No. 9140A27040310OC8501; No. 9140C850202100C8505).

\section{REFERENCES}

[1] C. S. Wu, Numerical Analysis of Welding Thermal Process. Harbin: Harbin Institute of Technology Press 1990.

[2] X. Q. Yin, J. Luo and H. G. Li, "Optimization of magnetic parameters for grain structure refinement of LD10CS aluminum alloy weldment", J. Xi'an Jiao Tong University, Vol. 33, pp. 71-74, July 1999.

[3] H. X. Wang, "Thermal efficiencies of fusion welding processes", Welding \& Joining, pp. 15-19, October 2007.

[4] Y. L. Chang, L. G. Shao, D. Li and D. Y. Li, "Research on MIG welding arc with additional longitudinal alternating magnetic field", Welding Technol., Vol. 38, pp.14-16, May 2009.

[5] N. S. Tsai and T. W. Eager, "Distribution of the heat and current fluxes in gas tungsten arcs", Metall. Trans. B, Vol. 16B, pp. 841846, April 1985.
[6] M. Arenas, V. L. Acoff and N. El-Kaddah, "Effect of arc length on weld penetration in GTA welding of gamma titanium aluminide", in Proceedings of the Conference, 2001, pp. 142-147.

[7] Q. Guan, W. X. Peng, J. D. Liu, Y. C. Shao and W. L. He, "Test method of effective utilization rate of Welding heat source", Transactions of the China Welding Institution, Vol. 3, pp. 10-23, March 1982.

[8] J. N. Dupont, and A. R. Marder, "Thermal efficiency of arc welding processes", Welding Journal, Vol.74, pp. 406-416, December 1995.

[9] Y. F. Fan, J. H. Liu, X. N. Luo and W. F. Xu, "Study on penetration of low power laser-TIG arc hybrid welded stainless steel”, Aeronautical Manufacturing Technol., Vol. 22, pp. 84-87, 2008

[10] S. Zhu, Q. W. Wang, F. L. Yin, Y. Y. Liang and X. M. Wang, "Numerical simulation of MIG welding arc with longitudinal magnetic field", in Sixth International Conference on Physical and Numerical Simulation of Materials Processing, 2010.

(C) Zhu et al.; Licensee Bentham Open.

This is an open access article licensed under the terms of the Creative Commons Attribution Non-Commercial License (http: //creativecommons.org/licenses/by$\mathrm{nc} / 3.0 /$ ), which permits unrestricted, non-commercial use, distribution and reproduction in any medium, provided the work is properly cited. 